\title{
HUBUNGAN PARASIT DI TANAH DENGAN KEBERADAAN PARASIT PADA KUKU PETANI SUMBER URIP 1 DESA WONOREJO KECAMATAN PONCOKUSUMO KABUPATEN MALANG
}

\author{
Edza Aria Wikurendra ${ }^{1}$, Merry Crismiati ${ }^{2}$ \\ Dosen S1 Ilmu Kesehatan Masyarakat Universitas Nahdlatul Ulama Surabaya, Mahasiswa Program \\ Studi S1 Kesehatan Lingkungan STIKES Widyagama Husada Malang \\ Email : edzaaria@unusa.ac.id
}

\begin{abstract}
This study aims to determine the relationship of parasites in the soil with the presence of parasites on the nails of farmers Sumber Urip 1 Desa Wonorejo. The research method used was analytic with Cross Sectional approach. The sample used were 18 Sumber Urip 1 farmers in Wonorejo Village. The sampling technique used was Total Sampling. Bivariate analysis uses pearson SPPS correlation with decision making using significant $<0.01$. The results of identification of parasites in 18 soil samples contained 12 positive samples of hookworm larvae and roundworm eggs. While the results of parasite identification in 18 nail samples of farmers there are 11 positive samples of hookworm larvae. From the results of Pearson correlation test on soil samples and nail samples Sumber Urip 1 farmers in Wonorejo village there was a relationship between parasites in the soil with the presence of parasites on the nails of Sumber Urip 1 farmers in Wonorejo village.
\end{abstract}

Keywords : Relationships, Parasites, Land, Farmers' Nails

\begin{abstract}
ABSTRAK
Penelitian ini bertujuan mengetahui hubungan parasit di tanah dengan keberadaan parasit pada kuku petani Sumber Urip 1 Desa Wonorejo. Metode penelitian yang digunakan adalah analitik dengan pendekatan Cross Sectional. Sampel yang digunakan adalah petani Sumber Urip 1 Desa Wonorejo yaitu 18 orang. Teknik sampel yang digunakan adalah Total Sampling. Analisa bivariat menggunakan korelasi pearson SPPS dengan pengambilan keputusan menggunakan hasil singnifikan $<0.01$. Hasil identifikasi parasit pada 18 sampel tanah terdapat sampel 12 sampel positif larva cacing tambang dan telur cacing gelang. Sedangkan hasil identifikasi parasit pada 18 sampel kuku petani terdapat 11 sampel positif larva cacing tambang. Hasil uji korelasi pearson pada sampel tanah dan sampel kuku petani Sumber Urip 1 Desa Wonorejo terdapat hubungan.
\end{abstract}

Kata kunci : Hubungan, Parasit, Tanah, Kuku Petani

\section{PENDAHULUAN}

Kecacingan merupakan penyakit infeksi disebabkan oleh parasit cacing yang dapat membahayakan kesehatan. Penyakit kecacingan yang sering menginfeksi dan memiliki dampak yang sangat merugikan adalah infeksi cacing yang ditularkan melalui tanah atau sering disebut "Soil Transmitted Helminths (STH)". Soil Transmitted Helminths sendiri masih dianggap tidak penting di masyarakat, karena dianggap tidak membahayakan atau menyebabkan kematian. Namun pada kenyataannya dampak dari infeksi Soil Transmited Helminths dapat menyebabkan penurunan kesehatan bahkan kematian (Depkes RI, 2010).

\section{Soil Transmitted Helminths}

(STH) merupakan istilah yang mengacu kepada 
sekelompok penyakit parasit yang disebabkan oleh cacing nematoda yang ditularkan kepada manusia melalui tanah yang terkontaminasi feses.

Jenis cacing yang ditransmisikan tanah yang menjadi perhatian utama bagi manusia adalah Ascaris lumbricoides, Trichuris trichiura, Necator americanus dan Ancylostoma duodenale. Prevalensi tertinggi terjadi di daerah dengan sanitasi tidak memadai dan air yang tidak aman (Wijaya, 2015).

Menurut WHO (2015), lebih dari 1,5 miliar orang atau sekitar $24 \%$ dari penduduk dunia mengalami infeksi Soil Transmitted Helminths (STH). Dimana lebih dari 270 juta anak usia pra-sekolah dan lebih dari 600 juta anak usia sekolah yang menderita infeksi Soil Transmitted Helminths (STH) dan membutuhkan perlakuan yang intensif. Di Indonesia, penyakit cacing adalah penyakit rakyat umum, infeksinya dapat terjadi secara simultan oleh beberapa jenis cacing sekaligus. Hasil survei kecacingan oleh Ditjen PP \& PL (2009) menyebutkan bahwa $31,8 \%$ siswa siswi SD menderita kecacingan. Dari data penyakit cacing 2017 di Puskesmas Poncokusumo Kabupaten Malang, terdapat 11 kasus penyakit cacing. Berdasarkan dari Ditjen PP \& PL (2012), untuk daerah dengan prevalensi sekitar $\geq 20 \%-<50 \%$, pemberian obat dilakukan secara massal kepada seluruh anak sekolah dasar di suatu kabupaten/kota satu kali dalam setahun. Apabila prevalensi $\geq 50 \%$ dilakukan pemberian obat cacing kepada seluruh anak sekolah dasar di suatu kabupaten/kota 2 kali dalam setahun.
Pengobatan selektif diberikan bila prevalensi $<20 \%$. Puskesmas Poncokusumo pada bulan april 2018 terdapat 689 orang di Desa Wonorejo membutuhkan obat cacing.

Infeksi cacingan Soil Transmitted Helminths (STH) salah satunya ialah lapangan pekerjaan yang berhubungan atau menggunakan tanah sebagai bahan baku utamanya karena tempat yang baik bagi Ascaris lumbricoides, Trichiuris trichiura Necator americanus, Ancylostoma duodenale, dan Strongyloides stercoralis adalah tanah yang lembab. Seringkali golongan pekerja pertanian (petani) yang langsung kontak dengan tanah mendapatkan infeksi kecacingan ini (Wijaya, 2015).

Petani sayur yang memiliki risiko terinfeksi penyakit cacingan ini yaitu kelompok tani Sumber Urip 1 Desa Wonorejo, dimana para petani hanya menggunakan sarung tangan yang terbuat dari kain dan penggunaan alas kaki berupa sepatu boot jarang digunakan.

Tujuan penelitian ini untuk mengetahui hubungan parasit di tanah dengan keberadaan parasit pada kuku petani Sumber Urp 1 Desa Wonorejo, Kecamatan Poncokusumo, Kabupaten Malang.

\section{METODE}

Penelitian ini merupakan penelitian Analitik dengan pendekatan Cross Sectional. Penelitian ini digunakan untuk mengetahui hubungan parasit di tanah dengan keberadaan parasit pada kuku petani Sumber Urp 1 Desa Wonorejo, Kecamatan Poncokusumo, Kabupaten Malang. 
Populasi penelitian ini adalah petani Sumber Urip 1 Desa Wonorejo dengan jumlah sampel 18 orang menggunakan teknik pengambilan sampel Total Sampling. Sampel pada penelitian ini berupa sampel tanah dan sampel kuku anggota petani Sumber Urip 1 Desa Wonorejo, Kecamatan Poncokusumo, Kabupaten Malang.

Instrumen dalam penelitian ini menggunakan observasi untuk data sekunder berupa karakteristik responden dan pemeriksaan laboratorium untuk data primer. Pemeriksaan laboratorium penelitian ini untuk identifikasi parasit di tanah pertanian petani Sumber Urip 1 Desa Wonorejo dengan menggunakan metode apung dan identifikasi parasit pada kuku petani Sumber Urip 1 Desa Wonorejo menggunakan metode sedimentasi.

Dalam penelitian ini, ada dua langkah pengolahan data, yakni pengolahan data manual dan pengolahan data dengan komputer.. Teknik analisa data menggunakan analisa univariat dan bivariat menggunakan uji korelasi pearson pada SPSS.

\section{HASIL DAN PEMBAHASASN}

\section{Karakteristik Responden}

Karakteristik responden pada penelitian ini dikelompokkan empat kategori yang berdasarkan jenis kelamin, usia, pendidikan dan masa kerja. Hasil observasi yang dilakukan terhadap 18 anggota petani Sumber Urip 1 Desa Wonorejo, Kecamatan Poncokusumo, Kabupaten Malang keseluruhan merupakan $100 \%$ berjenis kelamin laki - laki. Hal ini karena pada awal terbentuknya kelompok tani Sumber Urip 1 perempuan tidak tergabung sehingga saat ini anggota kelompok tani Sumber Urip 1 merupakan laki - laki.

Karakteristik usia responden sebagian besar usia anggota petani 45 - 50 Tahun dengan presentase $44.4 \%$. Hal ini kemungkinan terjadi karena orang-orang yang mau bekerja sebagai petani tidak berada pada kelompok umur remaja atau pun kelompok umur tua walau ada beberapa (Gultom, 2018).

$$
\text { Karakteristik tingkat pendidikan }
$$
anggota petani sebagian besar berpendidikan Sekolah Dasar (SD) dengan presentase 38.9\%. Hal ini menunjukkan bahwa masyarakat belum menganggap penting dan belum memiliki kesadaran dalam menyelesaikan pendidikan minimal sembilan tahun tanpa memandang jenis pekerjaan yang akan dijalaninya.

Karakteristik masa kerja seluruh anggota petani lebih dari 10 tahun dengan presentase $100 \%$. Masa kerja anggota Sumber Urip 1 lebih dari 10 tahun karena anggota petani Sumber Urip 1 merupakan anggota yang dari awal terbentukan kelompok hingga saat ini merupakan anggota lama dan tidak ada penambahan anggota baru.

\section{Hasil Identifikasi Parasit pada Tanah}

Hasil identifikasi parasit pada sampel tanah pertanian petani Sumber Urip 1 Desa Wonorejo Kecamatan Poncokusumo, Kabupaten Malang menggunakan metode apung dengan pengamatan hasil menggunakan mikroskop sebagai berikut :

Tabel 5.3.1 Distribusi Frekuensi hasil identifikasi parasit pada tanah 


\begin{tabular}{cccc}
\hline No & Hasil & Frekuensi & $\begin{array}{c}\text { Presentase } \\
(\%)\end{array}$ \\
\hline 1 & Positif & 12 & $66.7 \%$ \\
2 & Negatif & 6 & $33.9 \%$ \\
\hline Jumlah & 18 & $100 \%$ \\
\hline
\end{tabular}

Berdasarkan tabel 5.2.1 diketahui hasil pemeriksaan parasit pada tanah dengan jumlah sampel 18, terdapat hasil positif parasit 12 sampel dengan presentase $66.7 \%$ dan hasil negatif parasit 6 sampel dengan presentase 33.9\%. Hasil identifikasi sampel tanah yang positif parasit, ditemukan adanya larva cacing tambang dan telur cacing gelang sebagai berikut :

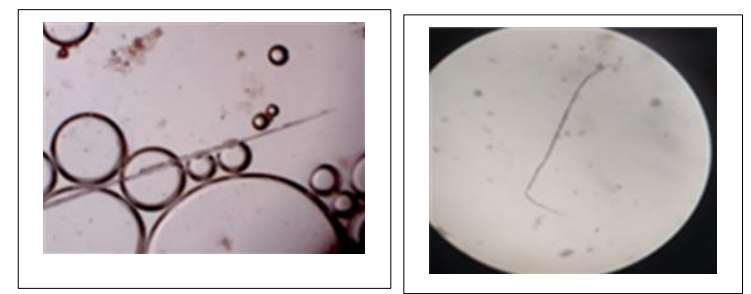

a. Gambar telur cacing gelang

b. Gambar larva cacing tambang

Cacing tambang merupakan salah satu jenis Soil Transmitted Helminths yang dapat dengan mudah menginfeksi inangnya karena selain telur, bentuk larva infektif dapat memasuki tubuh inang secara aktif. Lahan perkebunan, halaman sekolah dan pemukiman merupakan tempat - tempat dimana sering terjadi aktifitas manusia, adanya kontaminasi tanah oleh telur maupun larva cacing tambang ditambah dengan kurangnya kesadaran masyarakat untuk menjaga kebersihan diri saat beraktifitas di luar rumah akan semakin meningkatkan risiko penularan cacing tambang (Hairani, 2015).
Sedangkan cacing gelang secara umum tersebar di seluruh dunia, terutama di daerah tropis dan subtropis yang kelembaban udaranya tinggi. Telur cacing gelang ini dapat bertahan sampai 1 tahun dalam tanah (Soedarto, 2011). Dari hasil penelitian parasit pada tanah, terdapatnya larva cacing tambang dan telur cacing gelang karena daerah Desa wonorejo merupakan daerah dingin dan dekat dengan pengunungan sehingga kelembaban terhadap tanah tinggi. Bentuk tanah pertanian di Desa Wonorejo merupakan tanah yang gembur sehingga cocok untuk pertanian dan menjadi tempat perkembangan biak cacing tambang dan cacing gelang.

\section{Hasil Identifikasi Parasit pada Kuku Petani}

Hasil identifikasi parasit pada sampel kuku petani Sumber Urip 1 Desa Wonorejo Kecamatan Poncokusumo, Kabupaten Malang menggunakan metode sedimentasi dengan pengamatan hasil menggunakan mikroskop sebagai berikut :

Tabel 5.3.2 Dristribusi frekuensi hasil identifikasi parsit pada kuku

\begin{tabular}{cccc}
\hline No & Hasil & Frekuensi & $\begin{array}{c}\text { Presentase } \\
(\boldsymbol{\%})\end{array}$ \\
\hline 1 & Positif & 11 & $61.6 \%$ \\
2 & Negatif & 7 & $38.9 \%$ \\
\hline \multicolumn{2}{c}{ Jumlah } & 18 & $100 \%$ \\
\hline
\end{tabular}

Berdasarkan tabel 5.2.1 diketahui hasil

pemeriksaan parasit pada kuku petani Sumber Urip 1 dengan jumlah sampel 18, terdapat hasil positif parasit 11 sampel dengan presentase $61.1 \%$ dan hasil negatif parasit 7 sampel dengan presentase $38.9 \%$. Hasil identifikasi sampel yang postitif parasit pada 
kuku petani, ditemukan adanya larva cacing tambang sebagai berikut :

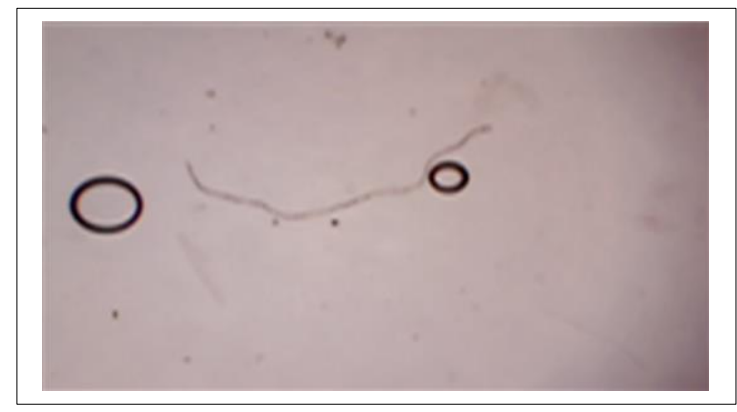

Gambar larva cacing tambang

Terdapatnya larva cacing tambang karena petani Sumber Urip 1 memiliki kuku yang kurang terawat dan pengolahan lahan pertanian tidak menggunakan sarung tangan.

Dikatakan larva cacing tambang karena berbentuk langsing panjang tubuhnya 600 mikron, berwarna putih ke abu-abuan dan rongga mulut tidak kelihatan sempurna. Sebaran cacing tambang sangat luas ke seluruh dunia, terutama daerah tropis dan subtropis yang bersuhu panas dan mempunyai kelembaban yang tinggi (Soedarto, 2011).

Cacing tambang merupakan salah satu jenis Soil Transmitted Helminths yang dapat dengan mudah menginfeksi inangnya karena selain telur, bentuk larva infektif dapat memasuki tubuh inang secara aktif (Hairani, 2015). Telur ataupun larva cacing sering kali terselip pada kuku yang kotor. Kondisi ini sering terjadi pada anak yang sering bermain ditanah serta pada orang dewasa yang bekerja dikebun atau disawah. Penularan infeksi cacingan bisa saja melalui kuku jari tangan yang panjang yang kemungkinan terselip telur cacing dan nantinya bisa tertelan ketika makan (Irawati, 2013).
Hubungan Parasit di Tanah dengan

\section{Keberadaan Parasit pada Kuku Petani}

Hasil uji korelasi yang dilakukan terhadap hasil identifikasi sampel tanah dan sampel kuku petani sebagai berikut :

Tabel 5.4 Hasil hubungan parasit pada tanah dengan parasit pada kuku petani

\begin{tabular}{|c|c|}
\hline Variabel & Korelasi Signifikasi \\
\cline { 1 - 1 } Sampel tanah & 0.004 \\
\cline { 1 - 1 } Sampel kuku & \\
\hline
\end{tabular}

Berdasarkan tabel 5.4 diketahui hasil uji korelasi pearson pada sampel tanah dan sampel kuku yang berjumlah masing - masing 18 sampel didapatkan singnifikan 0.004. Hasil signifikasi 0.004 lebih kecil dari 0.01 maka sampel tanah dan sampel kuku berkorelasi atau terdapat hubungan yang signifikasi.

Adanya hubungan parasit pada tanah dengan parasit pada kuku petani kemungkinan karena kebiasaan petani Sumber Urip 1 yang tidak menggunakan sarung tangan pada saat mengolah tanah pertanian, mencuci tangan tidak menggunakan sabun, pengetahuan petani tentang infeksi parasit atau cacing yang kurang dan penggunaan pupuk dari kotoran ternah sebagai penyubur tanah.

Pencemaran tanah merupakan penyebab terjadinya transmisi telur cacing dari tanah kepada manusia melalui tangan atau kuku yang mengandung telur cacing, lalu masuk ke mulut bersama makanan. Adanya lahan pertanian/perkebunan, kebiasaan penduduk dan pekerjaan penduduk dapat menjadi faktor risiko kejadian infeksi cacing tambang pada manusia. Larva cacing tambang dapat tumbuh dan berkembang dengan sangat baik pada tanah gembur disebabkan pada tanah gembur 
larva tersebut dapat dengan leluasa mengambil oksigen dibandingkan jika berada di tanah liat. Penggunaan pupuk kandang yang mengandung telur cacing pada lahan perkebunan kemungkinan menyebabkan kontaminasi tanah perkebunan oleh cacing tambang maupun jenis cacing lainnya (Hairani, 2015).

Gejala infeksi cacing tambang dapat disebabkan oleh larva maupun cacing dewasanya. Sesuai dengan tempat predileksinya, cacing tambang dapat hidup di rongga usus halus. Cacing tambang dewasa menyebabkan kehilangan darah secara perlahan-lahan. Hal tersebut disebabkan karena cacing dewasa dapat menghisap darah 0,2-0,3 cc setiap harinya. Sehingga pada infeksi yang kronis dapat menyebabkan anemia progesif, hipokromik mikrositter dan defisiensi besi. $\mathrm{Hb}$ dapat turun hingga 2 gr \%. Selain itu jika keadaan semakin buruk dapat menyebabkan sesak nafas, mudah lelah, pusing hingga kelemahan jantung. Larva cacing tambang dapat menembus kulit dan dapat menimbulkan rasa gatal (ground itch). Larva cacing tambang juga dapat bermigrasi ke paru dan menimbulkan pneumonitis. Infeksi A.duodenale lebih berat dari pada infeksi yang disebabkan oleh N.americanus (Noviastuti, 2015).

Dari penelitian Rahmawati (2009) menunjukkan bahwa ada hubungan yang signifikan antara memotong kuku seminggu sekali pemakaian alas kaki, cuci tangan sebelum makan dan kebiasaan mencuci kaki dengan kejadian kecacingan. Demikian halnya dengan Siregar Irham (2013) menujukkan bahwa ada hubungan kebiasaan mencuci tangan dengan sabun antiseptik dengan kejadian cacingan. Hanidy dan Fitri (2012) menunjukkan bahwa ada hubungan kebiasaan cuci tangan terhadap infeksi kecacingan. Infeksi kecacingan dapat dipengaruhi oleh higiene perorangan seperti kebersihan tangan dan kuku. Infeksi cacingan kebanyakan ditularkan melalui tangan yang kotor, kuku jemari tangan yang kotor dan panjang sering tersimpan telur cacing. Sejalan dengan teori yang dikemukakan Entjang (2003), Kebanyakan penyakit cacing ditularkan melalui tangan dan kaki yang kotor serta kuku yang panjang terselip oleh telur cacing (Jusuf,dkk. 2013).

Kebersihan diri yang kurang terutama kebiasaan defekasi dan sanitasi, status sosialekonomi renda, kurangnya tingkat pendidikan merupakan faktor resiko terjadinya infeksi cacing tambang. Perbaikan sanitasi, kebersihan dan kemoterapi telah membuat infestasi cacing tambang jarang ditemukan pada Negara maju, tetapi masih menjadi endemik di dunia (Ahmad, 2014). Infeksi cacing tambang dapat dicegah dengan memberikan obat cacing kepada penderita dan sebaiknya juga dilakukan pengobatan masal pada seluruh penduduk di daerah endemis. Pendidikan kesehatan diberikan kepada penduduk untuk membuat jamban yang baik untuk mencegah pencemaran tanah, dan jika berjalan di tanah selalu menggunakan alas kaki untuk mencegah terjadinya infeksi pada kulit oleh larva filarifom cacing tambang (Soedarto, 2011). 


\section{Keterbatasan Penelitian}

Dalam penelitian ini peneliti melakukan identifikasi kontaminasi parasit pada sampel tanah dan sampel kuku petani yang dilakukan hanya dengan satu kali uji tanpa dilakukan pengulangan, yang dimana semestinya uji laboratorium tidak dilakukan hanya satu kali saja tetapi dilakukan lebih dari satu kali agar bisa mendapatkan hasil yang lebih maksimal lagi.

Pada saat pengambilan sampel tanah dan kuku petani, peneliti tidak bertemu secara langsung dengan seluruh responden dikarenakan pada saat pengambilan sampel tanah responden tidak berada dilahan pertanian dan pada saat pengambilan sampel kuku responden tidak berada dirumah sehingga sampel kuku dikumpulkan kepada ketua kelompok tani.

Selain itu penelitian ini hanya dilakukan pada satu kelompok petani saja tanpa melakukan perbandingan dengan kelompok petani yang lain. Semestinya dilakukan perbandingan antara satu kelompok petani dengan kelompok petani yang lainnya agar kita bisa mengetahui apakah hasil yang didapatkan dari satu kelompok petani dengan kelompok petani yang lainnya itu sama atau justru ada perbedaan.

\section{KESIMPULAN}

1. Hasil identifikasi parasit pada 18 sampel tanah yang positif terdapat parasit 12 sampel dengan presentase $66.7 \%$ dan yang negatif terdapat parasit 6 sampel dengan presentase $33.9 \%$. Hasil identifikasi positif parasit pada 12 sampel tanah ditemukan adanya larva cacing tambang dan telur cacing gelang.

2. Hasil identifikasi parasit pada 18 sampel kuku petani yang positif terdapat parasit 11 sampel dengan presentase $61.6 \%$ dan yang negatif terdapat parasit 7 sampel dengan presentase $38.9 \%$. Hasil identifikasi positif parasit pada 11 sampel kuku petani ditemukan adanya larva cacing tambang.

3. Karakteristik petani Sumber Urip 1 Desa Wonorejo keseluruhan merupakan laki-laki dengan presentase $100 \%$ dengan usia anggota petani sebagain besar adalah $40-$ 50 Tahun dengan presentase $44.4 \%$ serta pendidikan sebagain besar anggota petani berpendidikan SD dengan presentase 38.9 $\%$ dan masa kerja anggota petani adalah > 10 Tahun dengan presentase $100 \%$.

4. Hasil uji korelasi pearson pada sampel tanah dan sampel kuku petani didapatkan hasil signifikan yang dimana parasit di tanah denga parasit pada kuku petani Sumber Urip 1 Desa Wonorejo terdapat hubungan.

\section{SARAN}

1. Bagi petani Sumber Urip 1 Desa Wonorejo perlu menggunakan sarung tangan dan alas kaki berupa sepatu pada saat mengolah lahan pertanian, mencuci tangan menggunakan sabun dan bagian kuku disikat agar kotoran yang menempel hilang, dan mengkonsumsi obat cacing.

2. Bagi Dinas Kesehatan agar melakukan penyuluhan atau memberikan informasi kepada petani yang berada di Desa Wonorejo mengenai manfaat penggunaan 
alat pelindung diri pada saat berkerja dan

kebersihan diri pada saat bekerja sehingga

mereka dapat terhindar dari penyakit salah satunya penyakit akibat parasit.

\section{DAFTAR PUSTAKA}

Depertemen Kesehatan RI. 2010. Profil Kesehatan Indonesia. Depkes RI. Jakarta

Ditjen PP \& PL. 2009. Pedoman Pengendalian Kecacingan. Kemenkes RI.Jakarta 2012. Profil Pengendalian Penyakit dan Penyehatan Lingkungan. Kemenkes RI

Entjang. 2003. Mikrobiologi dan Parasitologi untuk Akademi Keperawatan dan Sekolah Tenaga Kesehatan yang Sederajat, PT. Citra Aditya Bakti, Bandung

Gulton. 2018. Hubungan Kebiasaan Penggunaan Alat Pelindung Diri (Apd) Dan Personal Hygiene Dengan Kejadian Infeksi Kecacingan Pada Petugas Sampah Di Kota Medan Tahun 2017. Skripsi Fakultas Kesehatan Masyarakat Universitas Sumatera Utara Medan 2018

Hanidy dan Fitri. 2012. Analisis FaktorFaktor Resiko Infeksi Kecacingan Murid Sekolah Dasar di Kecematan Angkola Timur Kabupaten Tapanuli Selatan Tahun 2012. Universitas Sriwijaya

Irawati. 2013. Hubungan Personal hygiene Dengan Cacingan Pada Anak Di Wilayah Kerja Puskesmas Tamangapa Antang Makassar. Skripsi Fakultas Ilmu Kesehatan Universitas Islam Negeri Alauddin Makassar 2013 . http://repositori.uinalauddin.ac.id/3102/1/Irawati. pdf

Jusuf, Ruslan, dan Makmur. 2013. Gambaran Parasit Soil Transmitted Helminths Dan Tingkat Pengetahuan, Sikap Serta Tindakan Petani Sayur Di
Desa Waiheru Kecamatan Baguala Kota Ambon. Bagian Kesehatan Lingkungan FKM Universitas Hasanuddin

Noviastuti. 2015. Infeksi Soil Transmitted Helminths. Majority, Volume 4 Nomor 8, November 2015 107.

Rahmawati S, L. 2009. Hubungan Antara Sanitasi Lingkungan Rumah dan Praktek Kebersihan Diri Dengan Kejadian Kecacinga (studi kasus pada murid SD negeri Asinan 01 Desa Asinan kecamatan Bawen kabupaten Semarang). Universitas Diponegoro, Semaran

Siregar. 2013. Hubungan Personal Hygiene Dengan Penyakit Cacing (Soil Transmitted Helminth) Pada Pekerja Tanaman Kota Pekanbaru. Pusat Penelitian Lingkungan Hidup Universitas Riau.

Soedarto. 2011. Buku Ajar Parasitologi Kedokteran. Jakarta 